Koichi Koyama

\title{
Dendritic cell expansion occurs in mesenteric lymph nodes of B10.BR mice infected with the murine nematode parasite Trichuris muris
}

Published online: 11 August 2005

(C) Springer-Verlag 2005

\section{Parasitol Res (2005) DOI 10.1007/s00436-005-1427-2}

Unfortunately, Table 1 was published with errors. The correct Table 1 is given here.

Table 1 Kinetics of CD11 ${ }^{+}$B220- cells in MLNs of Trichuris muris-infected B10.BR mice

\begin{tabular}{llllll}
\hline Days p.i. & \multicolumn{2}{l}{ Percentage of positive staining cells } & Total cells isolated $\left(\times 10^{7}\right)^{\mathrm{b}}$ \\
\cline { 2 - 5 } & $\mathrm{CD}^{\mathrm{a}} \mathrm{c}^{+} \mathrm{B} 220^{-}$ & $\mathrm{CD}^{+}$ & $\mathrm{CD}^{+}$ & \multirow{2}{*}{$\mathrm{B}^{+} 20^{+}$} & \\
\hline Uninfected & $1.0 \pm 0.2^{c}$ & $39.2 \pm 1.4$ & $23.4 \pm 2.5$ & $32.0 \pm 2.9$ & $2.70 \pm 0.77$ \\
14 & $0.9 \pm 0.2$ & $39.1 \pm 2.5$ & $21.6 \pm 2.0$ & $35.3 \pm 4.9$ & $4.05 \pm 0.79^{*}$ \\
20 & $2.0 \pm 0.2^{* *}$ & $30.7 \pm 3.0^{* *}$ & $18.0 \pm 1.3^{* *}$ & $44.3 \pm 2.3^{* *}$ & $6.40 \pm 1.18^{* *}$ \\
25 & $1.0 \pm 0.3$ & $31.8 \pm 3.2^{* * *}$ & $18.6 \pm 2.3^{*}$ & $42.9 \pm 4.1^{* * *}$ & $4.55 \pm 0.65^{* *}$ \\
32 & $0.9 \pm 0.1$ & $36.7 \pm 3.3$ & $20.1 \pm 2.2$ & $38.6 \pm 4.7^{*}$ & $4.76 \pm 1.34^{*}$ \\
\hline
\end{tabular}

${ }^{a}$ MLNCs were prepared from the MLNs of uninfected or Trichuris muris-infected B10.BR mice on days 14, 20, 25, and 32 p.i. MLNCs were stained with PE-anti-CD11c and FITC-anti-B220 MoAbs, or PE-anti-CD4 and FITC-anti-CD8 MoAbs. Stained cells were then analyzed using a FACScan

${ }^{\mathrm{b}}$ Total numbers of mononuclear cells isolated from the MLNs of uninfected and infected mice

${ }^{c}$ Results represent the mean \pm SD for five mice at each time-point and are representative of three independent experiments that gave the similar results

$* P<0.05 ; * * P<0.01 ; * * * P<0.001$ compared with uninfected controls

The online version of the original article can be found at http:// dx.doi.org/10.1007/s00436-005-1427-2

K. Koyama

Department of Parasitology, Kitasato University School

of Medicine, 1-15-1 Kitasato, Sagamihara Kanagawa,

228-8555, Japan

E-mail: koyama@kitasato-u.ac.jp

Fax: + 81-42-7789312 